\title{
Influence of decadal sea surface temperature variability on northern Brazil rainfall in CMIP5 simulations
}

\author{
Julián Villamayor · Tércio Ambrizzi · Elsa \\ Mohino
}

6 Received: XXX / Accepted: XXX
7 Abstract The Amazonia and Northeast regions of northern Brazil are characterized by very different rainfall regimes but have certain similarities in terms of their variability. The precipitation variability in both regions is strongly linked to the tropical Atlantic sea surface temperature (SST) gradient and the tropical Pacific SST anomalies, which at decadal timescales are modulated by the Atlantic Multidecadal Variability (AMV) and the Interdecadal Pacific Oscillation (IPO) modes of SST, respectively. On the other hand, it has been found that state of the art models from the fifth phase of the Coupled Model Intercomparison Project (CMIP5) are able to reproduce some of the characteristics of the low-frequency SST variability modes. In this work we analyze how CMIP5 models simulate the observed response of precipitation in the Amazonia and Northeast regions to the AMV and the IPO and the atmospheric mechanisms involved. Results show that, in both CMIP5 simulations and observations, Amazonia and Northeast rainfall response to the AMV is the opposite, due to the modulation of the intertropical convergence zone (ITCZ) position. Conversely, the IPO affects equally both regions as a consequence of anomalous subsidence over the entire northern Brazil triggered by warm SST anomalies in the tropical Pacific. Such results suggest that an improvement of the predictability of decadal SST modes will directly revert into a better prediction of changes in the Amazonia and Northeast rainfall at longer timescales.

Keywords CMIP5 · Decadal variability · Northeast Brazil · Amazonia $\cdot$ AMV . IPO

J. Villamayor

Departamento de Geofísica y Meteorología. Facultad de C.C. Físicas , Universidad Complutense de Madrid (UCM), Pza de las Ciencias, 28040, Spain Tel.: +34-91-3944440

E-mail: julian.villamayor@ucm.es 


\section{Introduction}

The North of Brazil is a vast area with different rainfall regimes. Regarding the annual precipitation record, it can be broadly divided into two major regions: the Amazonia and Northeast Brazil. The former is the wet area covered by the Amazon River basin, where heavy rains typically accumulate annual records of over $2000 \mathrm{~mm}$ (Rao and Hada 1990; Ronchail et al 2002). The trade winds provide such wet conditions carrying moist air westward from the warm tropical Atlantic through the Amazon basin. The annual cycle of rainfall is closely related to the annual incursion of deep tropical convection associated with the Intertropical Convergence Zone (ITCZ), going from the southernmost part of the Amazonia toward the equator during and after the austral summer, respectively (Rao and Hada 1990; Ronchail et al 2002). The rainfall maximum goes from December at the southernmost part of the Amazonia, during the austral summer, to May and the beginning of the boreal summer at the north of the Brazilian Amazonia, around the equator. However, the region is prone to strong climate variability: rainfall regimes have alternated between wet and dry periods with marked decadal frequency and impacts on hydrological and environmental resources (Robertson and Mechoso 1998; Dettinger et al 2001; Marengo 2004; 2009).

The northeastern tropical region of Brazil (also referred to as Northeast Brazil) is mostly a plateau area with a semiarid precipitation regime, in which typically no more than $400 \mathrm{~mm}$ of precipitation per year are recorded (Kousky 1979; da Silva 2004). The rainy season in the Northeast is short, typically between March and May when the ITCZ reaches its southernmost position over this region (Moura and Shukla 1981; Zhou and Lau 2001; Rodrigues et al 2011; de Albuquerque Cavalcanti 2015). Then, the increase of convection and moisture advection associated with the ITCZ favors the occurrence of rainy events specially over northern and inner Northeast. The Northeast is particularly prone and sensible to changes on precipitation. Over the last century, this region has suffered recurrent long-term droughts and floods with severe humanitarian impacts (Hastenrath and Heller 1977; Hastenrath and Greischar 1993; Hastenrath 2012).

Rainfall variability in the Amazonia and Northeast regions has attracted the attention of several studies due to its relevant impacts (e.g., Rao and Hada 1990; Wainer and Soares 1997; Zhou and Lau 2001; Yoon and Zeng 2010; de Albuquerque Cavalcanti 2015). At interannual timescales, rainfall variability over the Amazonia and Northeast has been related to ITCZ changes induced by sub- and extratropical atmospheric modes (Hastenrath and Heller 1977; Moura and Shukla 1981; de Albuquerque Cavalcanti 2015). However there is wide agreement that the El Niño Southern Oscillation (ENSO) (Philander 1990) is the main modulator at these timescales due to anomalies on the Walker circulation driven by the tropical Pacific sea surface temperature (SST) (Zhou and Lau 2001; Souza and Ambrizzi 2002; Ambrizzi et al 2004; Kayano and Andreoli 2006; Rodrigues et al 2011).

The precipitation over the Amazonian and Northeast regions also varies on decadal timescales (Wainer and Soares 1997; Marengo et al 1998; Marengo 2004). This is related to anomalous shifts in the ITCZ position induced by changes at decadal to multidecadal timescales in both the interhemispheric contrast of tropical SST in the Atlantic and the tropical Pacific SST (Nobre and Shukla 1996; Wainer and Soares 1997; Robertson and Mechoso 1998; Zhou and Lau 2001; Marengo 2004; Andreoli and Kayano 2005; da Silva 2004). 
At decadal timescales, the main mode of SST variability modulating the ITCZ position over the Atlantic sector is the Atlantic Multidecadal Variability (AMV) (Knight et al 2006), also known as the Atlantic Multidecadal Oscillation (Kerr 2000). The AMV is a recurrent pattern of SST anomalies (SSTA), with respect to climatological SST values, in the North Atlantic with a period of roughly 60 years (Kerr 2000). During the warm (cold) phase of the AMV, the north Atlantic is anomalously warmer (colder) and the southern basin shows opposite anomalies creating a tropical interhemispheric SSTA dipole. Some works relate the AMV to the variability of the Atlantic meridional overturning circulation (Kerr 2000; Knight 2005; Parker et al 2007; Zhang and Wang 2013; McCarthy et al 2015), while others suggest an important role of the aerosols in forcing decadal changes of the Atlantic SST (Rotstayn and Lohmann 2002; Terray 2012; Booth et al 2012; Haywood et al 2013).

In relation to northern Brazilian rainfall, the characteristic interhemispheric SSTA dipole of the AMV is able to determine the southward excursion of the ITCZ during the austral summer and the following months (Knight et al 2006). During warm AMV phases the tropical SSTA gradient hinders the typical southern maximum displacement of the ITCZ during the rainy season in Northeast, which remains next to the mouth of the Amazon River (Knight et al 2006). Whilst opposite effects on the ITCZ and rainfall occur during cold AMV phases. According to this, it has been shown there exists a negative relationship between the AMV phases and Northeast precipitation anomalies (Knight et al 2006) as well as suggested an intensification of the intraseasonal rainfall anomalies in the Amazonia region (Good et al 2008).

Regarding decadal variability of Pacific SST, the leading mode of variability in the detrended SSTA of the Pacific basin at decadal timescale is termed the Interdecadal Pacific Oscillation (IPO) (Zhang et al 1997; Power et al 1999). Some authors refer to the Pacific low-frequency variability as the Pacific Decadal Oscillation, which is the signal of the IPO defined with the SSTA in the northern basin during the boreal winter (Mantua et al 1997; Newman et al 2016). The SSTA pattern during the positive (negative) phase of the IPO shows an ENSO-like warm (cold) tongue from the eastern to the western tropical Pacific and two cold (warm) tongues in the extratropics, with a horseshoe shape of opposite anomalies along the west coast of North and South America (Trenberth and Hurrell 1994; Meehl et al $2009 \mathrm{~b})$. However there is currently no consensus as to the mechanisms that generate this pattern (Deser et al 2004; Meehl and Hu 2006; Farneti et al 2014; Newman et al 2003; Schneider and Cornuelle 2005; Shakun and Shaman 2009). The IPO has no well-defined unique frequency, but some periodicities that can be grouped in a decadal and a multidecadal range of 15-25 and 60-70 years, respectively (Minobe 1999; Chao et al 2000; Tourre et al 2001; Mantua and Hare 2002; MacDonald and Case 2005).

The IPO is also related to changes in the Amazonia and Northeast regions at long-term timescale. According to some studies, the relationship between the IPO and northern Brazilian rainfall comes from the ability of the IPO to modulate the occurrence and intensity of ENSO events (Dettinger et al 2001; Marengo 2004; Andreoli and Kayano 2005; Rodrigues et al 2011). Nevertheless, the SSTA pattern associated with the positive (negative) IPO phase is directly related to anomalous dry (wet) conditions over both the Amazonia and Northeast regions (Dettinger et al 2001). Such connection is linked to negative (positive) low-level pressure 
anomalies over the tropical Pacific and less (more) river flow in northern South America, suggesting an ENSO-like atmospheric mechanism (Dettinger et al 2001).

At longer timescales, the long-term trends of the Northeast rainfall have been found to be insignificant (da Silva 2004) and, because of the short sample of the observed data available, they are suggested to be part of the interdecadal changes (Zhou and Lau 2001). In the Amazonia, there are some discrepancies about the long-term precipitation trends, which are also suggested to be non significant compared to the decadal changes (Marengo 2004; 2009).

In the last decade, there have been several attempts to predict decadal variations of the climate system using initialized coupled model simulations with very little skill for rainfall over land (Newman 2013; Meehl et al 2009a; Doblas-Reyes et al 2013; Gaetani and Mohino 2013). The prediction of such decadal variations of rainfall over the Amazonia and Northeast regions could be very valuable for planning for energy resources management, agriculture and prevention of natural disasters such as floods or droughts. To provide skillful estimates, models need to correctly reproduce the evolution of SST decadal modes and also their impact. Models show skill in reproducing SST evolution in some regions, like the Atlantic (Hawkins et al 2011; Latif and Keenlyside 2011; van Oldenborgh et al 2012). Several works have already addressed the ability of state-of-the-art global coupled models in reproducing the characteristics of the AMV and IPO modes and some of their impacts (e.g., Zhang and Wang 2013; Martin et al 2014; Villamayor and Mohino 2015; Fuentes-Franco et al 2015; Yim et al 2015; Zhang and Delworth 2015; Farneti 2017; Joshi and Kucharski 2017). Nevertheless, to our knowledge none has analyzed the impacts over the Amazonia and Northeast regions.

The main aim of this work is to show the observed direct impact that the AMV and IPO modes of SST have on rainfall in the Amazonia and Northeast regions during the common rainy months, from December to May (hereinafter DJFMAM), the atmospheric dynamic mechanisms involved and to determine whether the state-of-the-art models are able to reproduce such connection. Our specific objectives are: (1) To analyze the reproduced multi-model mean links between the AMV and IPO with the Amazonia and Northeast rainfall, comparing them to the observed ones. (2) To look into the associated atmospheric dynamics in the models and its consistency with observations. (3) To discuss the possible differences between externally forced and unforced simulations and seek whether in the future projections given by the models these relationships are expected to change or not.

\section{Data and methods}

\subsection{Simulations}

In this work we analyze output data from some common experiments of a set of 17 different state-of-the-art global coupled models participating in the Coupled Model Intercomparison Project Phase 5 (CMIP5) (Taylor et al 2012) (Table 1). CMIP5 brings together diverse coordinated experiments and involves 20 international modeling groups, providing a multi-model setting of simulations including some long-term experiments ideal to study the decadal to multidecadal climate variability (Table 1). The experiments analyzed in this work are the long-term 
unforced preindustrial control (hereinafter piControl) run, the 20th century simulation (typically from 1850 to 2005) which includes the observed external forcing (hereinafter historical) and the future projection (typically from 2006 to 2100) of Representative Concentration Pathway 8.5 (hereinafter RCP8.5), with a radiative forcing rising up to $8.5 \mathrm{~W} / \mathrm{m}^{2}$ in 2100 induced by the emission of global warming gases (Riahi et al 2007) (more details in Table 1). We use monthly output data of SST, precipitation, surface pressure, winds and specific humidity at various levels that are interpolated to a common grid of $2.8^{\circ}$ in latitude and longitude and 17 vertical levels. We also calculate the moisture flux as the mass-weighted vertical integration between the surface and the $200 \mathrm{hPa}$ level of the specific humidity times the vector wind at each level.

\subsection{Observations}

For observations we use monthly SST data from the Hadley Center sea ice and sea surface temperature version 1 (HadISST1, from 1870 to 2009) (Rayner et al 2003). HadISST1 is a reconstruction of SST data from the Met Office Marine Data Bank, the International Comprehensive Ocean-Atmosphere Data Set and satellite measurements from 1982 onwards, interpolated to a fully spatially distributed grid with a resolution of $1^{\circ}$ in longitude and latitude.

The available records of observed precipitation in the Amazonia region are sparse and inaccurate in some cases, especially during the early $20^{\text {th }}$ century (Marengo 2004). The precipitation gridded data use selected observations and provide long time series by spatially interpolating the available stations records. But in turn, this artificial reconstruction generates high uncertainty of the resulting data in regions with scarce observations. Therefore, to gain confidence on the observational results with which we compare the CMIP5 simulations, three gridded data sets dealing with different interpolation methods are analyzed. One is the Version-7 of the Global Precipitation Climatology Centre (GPCC v7, from 1901 to 2013) (Schneider et al 2016), another is the Climatic Research Unit time series version 3.24.01 (CRU TS3.24.01, from 1901 to 2015) (Harris et al 2014) and the third one is the University of Delaware Air Temperature and Precipitation version 4.01 (UDEL v4.01, form 1900 to 2014) (Willmott et al 2001). The three are monthly databases of continental coverage with a longitude and latitude resolution of $0.5^{\circ}$ based on precipitation data from weather stations distributed around the world.

In order to study the atmospheric dynamics, data for surface pressure, winds and specific humidity at different levels from reanalysis are used. These are based on the assimilation of observational data and, therefore, also have inherent uncertainties that are mainly attributed to the model and the observations used. To deal with it, we use two different reanalysis to compare the results: the European Center for Medium-Range Weather Forecasts reanalysis of the 20th Century (ERA-20C, from 1900 to 2010) (Poli et al 2013) and the NOAA-CIRES $20^{\text {th }}$ Century Reanalysis version 2c (20CRV2c, from 1851 to 2014) (Compo et al 2011). Both reanalyses are performed by assimilating surface pressure from the International Surface Pressure Databank and the ERA-20C also includes wind observations from the International Comprehensive Ocean-Atmosphere Data Set. The outputs used from both reanalyses are monthly data with a horizontal resolution of $1^{\circ}$ in longi- 
tude and latitude and 37 and 24 vertical levels, respectively for the ERA-20C and the 20CRV2c.

\subsection{Indices and patterns}

The AMV and the IPO indices are calculated from the simulated and observed annual SSTA data following Villamayor and Mohino (2015): Firstly, we eliminate an estimate of the global warming (GW) influence from the SSTA field as in Mohino et al (2011). To that end, we obtain the GW spatial pattern by regressing the annual SSTA field onto the GW index, calculated as the 40 year low pass-filtered global mean SSTA (between $45^{\circ} \mathrm{S}$ and $60^{\circ} \mathrm{N}$ ). Then we calculate a "GW-fitted" SSTA field as the product of the GW spatial pattern times the GW index and subtract it from the original field to get a "residual" SSTA field with removed GW influence. Finally, the AMV and IPO indices are computed as the first principal component of an Empirical Orthogonal Function (EOF) analysis of the "residual" SSTA in the North Atlantic (between $0^{\circ}$ and $60^{\circ} \mathrm{N}$ ) and the Pacific basin (between $45^{\circ} \mathrm{S}$ and $60^{\circ} \mathrm{N}$ ), respectively. The "residual" SSTA field is previously area weighted and low pass-filtered with a 13-year cutoff period. As an exception, in the case of the unforced piControl simulations the AMV and IPO indices are calculated from the original SSTA field instead of the "residual". For those models with several realizations of the same experiment (see Table 1), their simulations are concatenated in time before the AMV and IPO estimation. In this way we seek to take advantage of the information provided by all the ensemble members. Furthermore, hardly any differences are found between the SSTA patterns and the time series obtained with this method and by analyzing the ensemble members separately and then averaging the patterns and putting the indices in series, respectively (not shown).

The spatial patterns of the diverse variables associated with the AMV and IPO are obtained by regressing the unfiltered anomalous fields onto the respective indices. For the SSTA patterns, the annual values of the original data have been used for the regression. Whilst for the atmospheric variables, the regression maps have been computed using the seasonal anomaly during the DJFMAM season of maximum precipitation common to both Amazonia and Northeast regions. In the case of the Northeast region, its short rainy season is restricted to the months from March to May. However, the results concerning this region do not change substantially whether we use the anomalies averaged in DJFMAM or in its characteristic rainy season (not shown).

\subsection{Statistical significance}

To assess the statistical significance of regression patterns a "random-phase" test, based on Ebisuzaki (1997), is used. This test is based on the comparison between the regression at each grid point and a distribution of 100 regression coefficients obtained from random series designed to preserve the autocorrelation of the original ones. These series are generated by randomly altering the phase of the original ones, using Fourier transforms, and maintaining their periodicities. For the multi-model analysis, model-mean regression patterns across the 17 models are 
composed to show the common impacts of the AMV and IPO reproduced by the CMIP5 models. To evaluate the statistical significance of these model-mean patterns, the "random-phase" test is adapted. In this case, the averaged regression is compared with a probability density function constructed from mean regression coefficients out of 17 pairs of random time series generated from the original ones of each model.

\section{Results}

\subsection{AMV}

\subsubsection{SSTA pattern and rainfall response}

The observed AMV pattern is characterized by a well-defined interhemisferic SSTA gradient in the Atlantic basin, with warm anomalies all across its northern half and cold ones in the southern part (Figure 1a). The North Atlantic warming depicts a comma-shape pattern of SSTA. Anomalies are more intense in the northernmost part of the North Atlantic, south of Greenland, and extend southward along the eastern part of the basin to the northern half of the tropical Atlantic. The rainfall response to the AMV during DJFMAM is anomalously negative over the Northeast of Brazil and positive in most of the vast Amazonia region and further north (Figure 1b). Although the regression pattern shows low statistical significance, the observed rainfall response to the AMV is consistent among the three data bases analyzed (supplementary Figures S1a-d). The negative link between the AMV and rainfall over the Northeast is related to an anomalous latitudinal positioning of the ITCZ, which remains too far north close to the equator due to the northward SSTA dipole of the AMV pattern (Knight et al 2006). The meridional SSTA gradient is also related to changes in the ITCZ over the Amazonia region and the moisture supply (Yoon and Zeng 2010; Good et al 2008), as well as to rainfall anomalies in the Guianas and Venezuela (Hastenrath and Heller 1977).

In agreement with observations, the CMIP5 models reproduce an AMV pattern of SSTA averaged across the 17 models that shows the described comma-shape anomalous warming at the North Atlantic with high consistency among the models in both the historical and piControl simulations (crosses in Figures 2a and 2c indicate the grid points where most of the models coincide in the sign of the regression coefficient). However, the models tend to underestimate the anomalies of this pattern, especially in the tropical and subtropical North Atlantic. There are also some differences between the two experiments. Over the southern half of the Atlantic Ocean, in the AMV pattern of the historical experiment there are weak and not significant anomalies. In contrast, the pattern of the piControl one shows significant cold SSTA south of the equator, with high consistency among the models and in agreement with the observed pattern. This result suggests that most of the models reproduce a more accurately defined SSTA interhemispheric gradient in the Atlantic in the piControl experiment than in the historical one. In the historical experiment, the AMV pattern shows mostly positive SSTA in the Indian Ocean, which are more consistent among the models in the northeastern part of the basin. It also shows significant warm anomalies in the northernmost part of the Pacific Ocean and weak ones in roughly the rest of the basin. On the other 
hand, the piControl AMV pattern shows weaker warm SSTA over the northern Indian Ocean and significant cooling to the south. In the Pacific, it also shows a significant extratropical warming to the north in agreement to the historical AMV pattern, but in contrast a cooling to the south (Figure 2c).

Consistently with the observed precipitation pattern, the CMIP5 models on average reproduce drier conditions in Northeast and wetter in the Amazonia region associated with the positive AMV SSTA pattern in both the historical and piControl simulations (Figures $2 \mathrm{~b}$ and $2 \mathrm{~d}$ respectively). The full-scale rainfall pattern in northern Brazil and the tropical Atlantic depicts a fringe of negative rainfall anomalies along the tropical Atlantic below the equator, covering the Northeast, and another of positive anomalies over the equator, extending across the northern half of the Amazon (north of $7^{\circ} \mathrm{S}$ ). Such anomalous latitudinal shift of the tropical rain-belt suggests that the CMIP5 models reproduce ITCZ changes over northern South America in response to the characteristic tropical Atlantic SSTA dipole of the AMV (Folland et al 2001; Knight et al 2006).

Note that the scale used to display the rainfall anomalies of the ensemblemean regression patterns (ranging from around -0.1 to $0.1 \mathrm{~mm} /$ day per standard deviation) is lower than the one used for observations (from -0.5 to $0.5 \mathrm{~mm} /$ day per standard deviation). The averaging among the 17 precipitation patterns of the models, which may present certain discrepancies in the sign and amplitude of the regression coefficients in the different grid points, can explain the underestimation of the anomalies in the model-mean patterns with respect to observations. Besides, some CMIP5 models individually underestimate the intensity of rainfall, especially in the Amazonia, due to unrealistically reproduced moisture transport related with inaccurate representation of surface radiative fluxes or with overestimation of the tropical convective rainfall over the surrounding Pacific and Atlantic oceans (Yin et al 2013).

Although the precipitation anomalies are similarly distributed in the regression maps of both the forced and unforced experiments, there are some differences between them. Roughly, the most outstanding difference is that the model-mean rainfall response to the AMV of the historical experiment is less statistically significant and consistent among models than the one of piControl. In the historical experiment, there are positive and negative rainfall anomalies over most of the Amazonia and over the Northeast region, respectively, but without high statistical significance in both regions (Figure 2b). In contrast, in the piControl experiment there are highly significant positive and negative precipitation anomalies over Amazonia, north of $5^{\circ} \mathrm{S}$, and over the Northeast region, respectively (Figure $2 \mathrm{~d})$.

The fact that the rainfall pattern of piControl runs are, on average, more significant and therefore more consistent between the models than the one from historical simulations may be related to the differences between the AMV patterns obtained for both experiments. But which are the features of the AMV pattern that differ from one experiment to another that induce the differences in the precipitation response? To answer this question, in the following we analyze the AMV patterns simulated by the different models. 


\subsubsection{Inter-model analysis}

One of the main differences in the model-mean AMV patterns of SSTA between the historical and the piControl experiments were found in the interhemispheric thermal gradient in the tropical Atlantic. This feature of the SSTA pattern is key to determine the rain in the Amazonia and Northeast regions (e.g., Good et al 2008; Folland et al 2001), it could thus affect the way in which the models reproduce the link between the AMV and rainfall in the different experiments.

In most models the reproduced tropical Atlantic SSTA gradient of the AMV pattern is less than $30 \%$ of the observed value (of around $0.16^{\circ} \mathrm{C}$ per standard deviation), being only comparable (higher than the $60 \%$ of the observed gradient) in the piControl runs of the HadGEM2-CC and HadGEM2-ES models and the MIROC-ESM-CHEM in both experiments (in Figure 3, numbers 9, 10 and 14, respectively). Coinciding with this, the models generally also underestimate the rainfall response to the AMV or even reproduce opposite anomalies with respect to the observations. Over the Amazonia region they reproduce less than half the observed precipitation anomalies and in the Northeast only the HadGEM2-CC model in the two experiments and the HadGEM2-ES, MIROC5 and NorESM1-M in their piControl simulations reproduce rainfall anomalies that are similar or more intense than the observations (in Figure 3, numbers 9, 10, 13 and 17, respectively).

Focusing on the relationship between the tropical SSTA gradient of the AMV pattern and the precipitation response in the Amazonia and Northeast regions reproduced by the models individually, the piControl experiment shows strong linear correlation (the correlation coefficients are $R=0.81$ and $R=-0.71$ in the respective regions, which are significant with a $95 \%$ confidence level from absolute values higher than $\mathrm{R}=0.48$, according to a Student t-test) (Figure 3 ). However, the HadGEM2-CC model (number 9) reproduces lower Amazon rainfall response despite showing even stronger SSTA. This may be attributed to a weakly reproduced sensitivity of the atmosphere in this region to the SST by the model or to observed data uncertainties that lead to overestimated results. Regarding the Northeast precipitation response, this linear relationship strongly (but not totally) depends on the result of the HadGEM2-CC model, which shows an outstanding strong link with the SSTA gradient. In contrast, there seems to be no such link in the historical experiments (linearly correlated with $\mathrm{R}=0.35$ and $\mathrm{R}=0.04$ respectively in the Amazonia and Northeast). In agreement with Martin et al (2014), we also find that the first low-frequency variability mode of the North Atlantic SSTA reproduced by some models is not associated with an AMV-like SSTA pattern, i.e. with a well defined interhemispheric gradient of SSTA over the Atlantic (supplementary Figures S2 and S3). Furthermore, the differences found between the historical and piControl experiments in the model-mean AMV patterns of SSTA are not appreciable in all the models individually, suggesting an important model dependence.

These results suggest that the fact that some models do not reproduce a welldefined AMV pattern of SSTA can explain the uncertainties among the models in the precipitation response of the piControl experiment (supplementary Figure S5). In some cases these patterns show certain relationship between the AMV and the SSTA of other basins, such as the Pacific (Zhang and Delworth 2007; Wu et al 2011; Levine et al 2017), which may interfere with the rainfall response to the Atlantic SSTA gradient. Regarding the historical experiment, another source of 
uncertainty needs to be considered: The aerosols seem to play a relevant role in explaining the differences between the characteristics of the AMV patterns of the historical and piControl experiments (Booth et al 2012; Zhang et al 2013) (more details in the discussion of the supplementary material).

\subsubsection{Atmospheric teleconnection between AMV and rainfall}

The AMV observed signal projects onto a surface low and associated low-level cyclonic circulation over the Atlantic north of the equator, while it shows positive surface pressure anomalies to the south (Figure 4a). Associated with this pressure gradient, there are northward anomalous low-level winds over the western part of the tropical Atlantic and northern South America. These winds are, in turn, consistent with the anomalous moisture flux from the tropical Atlantic toward the Amazon River mouth and inland (Figures $4 \mathrm{a}$ and $4 \mathrm{~b}$ ). This low-level and the high-level (not shown) circulation also suggest an anomalous meridional circulation with stronger convection over the northern and subsidence over the southern Atlantic basin associated with the decrease and increase of surface pressure, respectively. This anomalous circulation entails the strengthening of the ITCZ north of the equator, reducing the moisture supply in the Northeast (Moura and Shukla 1981; Hastenrath and Greischar 1993; de Albuquerque Cavalcanti 2015) (Figure 4b). Not only is this mechanism consistent with the anomalous drying of the Northeast (Knight et al 2006) but also with wetter conditions in the Amazonia region. The northward displacement of the ITCZ provides Amazonia with more humidity advected from the tropical Atlantic toward the Amazon River mouth and inland.

Consistent with the AMV patterns of SSTA, the model-mean surface pressure response in the historical experiment shows lower statistical significance over the southern Atlantic (between $0^{\circ}-40^{\circ} \mathrm{S}$ ) than in the piControl one. The models reproduce the anomalous cyclonic circulation over the North Atlantic and a surface pressure contrast with respect to the south (Figures $4 \mathrm{c}$ and $4 \mathrm{e}$ ), in agreement with observations. However, the North Atlantic cyclone displayed by the surface pressure and low-level wind anomalies is placed more to the northeast than in observations. This is consistent with the distribution of the SSTA in the AMV patterns throughout the tropical North Atlantic. In observations the stronger SSTA are closer to the equator than in the historical and piControl simulations, which are located more to the north (Figures 1a, 2a and 2c, respectively). Despite this difference, the models reproduce the observed anomalous northward shift of the cross-equatorial winds and the moisture flux away from the Northeast of Brazil and toward the Amazon basin (Figures 4d and 4f).

The most remarkable discrepancies between the observed and simulated atmospheric circulation response to the AMV are shown over the interior of the South American continent. The observations show uncertain surface pressure response over South America but consistent northwesterly low-level anomalous wind and moisture flux along Bolivia and central Brazil, between $10^{\circ}-20^{\circ} \mathrm{S}$ (Figures 4a-b and supplementary Figures S1e and S1g). This jet of anomalous low-level wind and humidity flows southeastward from western Amazonia along the eastern slope of the Peruvian Andes. Such anomalies, in turn, could be related to changes in the low-level winds and the moisture transport over this area, which are associated with the South American monsoon system and are related to climate variability in subtropical and extratropical regions of the continent (Labraga et al 2000; Grimm 
and Zilli 2009; Marengo et al 2012). The models also simulate a northward deviation of the easterly moisture flux over the Amazon basin, instead of flowing to the south of the Amazonia region and to the east through central Brazil as shown by the observations. Such discrepancies do not affect the Northeast and the northern part of the Amazonia, which are mostly influenced by the easterlies from the tropical Atlantic, but can substantially affect the way in which CMIP5 models reproduce the relationship between the AMV and rainfall in the south of the Amazonia, as well as other extratropical regions (Marengo et al 2012), and thus its low-frequency variability.

\section{$3.2 \mathrm{IPO}$}

\subsubsection{SSTA pattern and rainfall response}

The observed IPO pattern is characterized by significant warm SSTA in the tropical Pacific, with an ENSO-like shape, extending to the extratropics along the western coasts of both North and South America (Figure 5a). It also presents two cold tongues of SSTA in mid-latitudes expanding eastward from the coasts of Asia and Oceania, respectively. The simulations show IPO patterns highly consistent with the observed one (Figures 6a and 6c). Away from the Pacific basin the anomalies are less intense. There is widespread warming of the Indian Ocean surface in observations and simulations. In the Atlantic basin there are weak and non significant observed anomalies, although the simulations produce a small but statistically significant heating in the tropical sector. The model-mean IPO pattern of the piControl experiment is found to be slightly more consistent among the models than the historical one. However, there is little difference between the patterns from both sets of experiments. Regarding the preferred frequency of the IPO indices, models, on average, tend to show higher power spectra in the bands of 15-25 and 50-70 years, though the level of agreement is low (Villamayor and Mohino 2015). Such bands are roughly consistent with the observations (Minobe 1999; Chao et al 2000; Tourre et al 2001; Mantua and Hare 2002; MacDonald and Case 2005).

The observed precipitation anomalies related to the IPO during DJFMAM show significant deficit in the Amazonia and Northeast regions (Figure 5b). In the Amazonia region the rainfall anomalies are mostly spread across the entire area, being more intense over the western side. In the Northeast of Brazil the stronger negative anomalies are distributed along the coastal part of the region, especially at the northwest, and decrease in magnitude inland. This result coincides with the impact on rainfall in both the Amazonia and Northeast regions produced by the SSTA pattern of ENSO (e.g., Ambrizzi et al 2004) which is similar to the tropical Pacific component of the IPO and agrees with other works that suggest a similar connection at decadal-to-multidecadal timescales (Dettinger et al 2001). In addition to this, the observations also show significant positive precipitation anomalies associated with the IPO over central Brazil as well as in the north and south of the Amazon Basin: over Venezuela and Bolivia, respectively.

Both historical and piControl experiments present an impact of IPO on rainfall in both the Amazonia and Northeast regions during DJFMAM similar to the observed one, though underestimated in intensity (Figures $6 \mathrm{~b}$ and $6 \mathrm{~d}$ ). In the 
Amazon basin the model-mean rainfall response is negative across most of the region. However, in contrast to the observations, the anomalies are more intense and consistent among the models to the east in both the historical and piControl experiments. In the historical experiment, the precipitation anomalies over the Amazon region associated with IPO are lower than in piControl, especially in the southwestern part where the anomalies are not significant only in the historical simulation. In the Northeast, the models reproduce on average a significant decrease of rainfall across the region with high agreement among the models. In both historical and piControl experiments the precipitation anomalies are similarly distributed, being stronger in the western half of the Northeast region. Nevertheless, these anomalies are more intensely reproduced by the historical simulations which also show stronger negative anomalies over the western edge of the region than the piControl experiment.

Out of northern Brazil, the models reproduce positive rainfall anomalies south of the Amazonia and in central Brazil, as in observations. However the rainfall response given by the models in these areas is much weaker than the observed one, indicating certain disagreement among models. North of the Amazonia region, over Venezuela they reproduce negative anomalies (contrary to observations) and show very robust negative signal over southern Central America, in Costa Rica and Panama, in agreement with observations.

In both the historical and piControl experiments, there is a strong intensification of precipitation along the tropical Pacific between $0^{\circ}-10^{\circ} \mathrm{S}$, which affects the western slope of the Andes. In contrast, over the Atlantic there is a weakened tropical rain-belt around $5^{\circ} \mathrm{S}$ that expands westward inland. This suggests that the CMIP5 models reproduce a strengthening of the ITCZ over the warm tropical Pacific and a weakening over the Atlantic and northern Brazil during DJFMAM associated with the IPO pattern.

\subsubsection{Inter-model analysis}

Despite the robustness of the IPO SSTA pattern reproduced across all the models (Figures 6a and 6c), the simulated precipitation response over the Amazonia and Northeast regions is less consistent among the models (Figures $6 \mathrm{~b}$ and $6 \mathrm{~d}$ ). Regarding the models individually, roughly half of them (CanESM2, CSIRO-Mk3-6-0, HadGEM2-ES, IPSL-CM5A-LR, MIROC5, MIROC-ESM-CHEM, MPI-ESM-LR) broadly reproduce negative anomalies along the tropical Atlantic sector and inland similarly in both experiments (supplementary Figures S6 and S7). The precipitation patterns linked to the IPO of these models roughly show a weakened tropical rain-belt over the north of South America, suggesting an anomalous weakening of the convective rainfall associated with the ITCZ as in the model-mean pattern. However, other models reproduce precipitation patterns that are noisy or present weak anomalies (CNRM-CM5, FGOALS-g2, GISS-E2-H, GISS-E2-R), others display opposite rainfall response to the observed one in some of the two regions of northern Brazil (inmcm4, MRI-CGCM3, CCSM4, NorESM1-M) and there are only two that do not show a consistent rainfall response in the two different experiments (bcc-csm1-1 and HadGEM2-CC).

The differences among the models in the simulated impact of the IPO on the Amazonia and Northeast rainfall can be attributed to the accuracy with which they reproduce the IPO pattern with respect to the observed one. Particularly, focusing 
on the link between the precipitation response to the IPO and the characteristic tropical Pacific component of the SSTA pattern, we find that there is a linear relationship (Figure 7). In the Amazonia region, such a relationship is weaker in the historical than in the piControl experiment (linearly correlated with $\mathrm{R}=-0.41$ and $\mathrm{R}=-0.64$, respectively) (Figure $7 \mathrm{a}$ ). This is consistent with the fact that the robustness of the SSTA pattern among the models is slightly weaker in the forced than in the unforced simulations (Figures 6a and 6c). In case of the Northeast precipitation, the relationship between precipitation and the IPO pattern is similar in both the historical and piControl experiments (linearly correlated with $\mathrm{R}=-$ 0.41 and $\mathrm{R}=-0.40$, respectively) (Figure $7 \mathrm{~b}$ ). The linear fit between the rainfall response to the IPO and the tropical Pacific component of the SSTA pattern in all cases is not highly significant (the correlation coefficients with an absolute value of $\mathrm{R}=0.40$ are barely significant with a $90 \%$ confidence level, according to a Student t-test). But it has to be considered that the IPO pattern shows significant loads of SSTA away from the Pacific and hence there are other domains that may also contribute to influence the connection with rainfall. There are also some models that, although they reproduce sufficiently intense tropical Pacific SSTA, the rainfall response is weaker than in observations. This therefore suggests that either the observational result is overestimated due to data uncertainties or that models reproduce insufficient atmospheric response to SSTA.

Therefore, this result suggests that the accuracy with which the models reproduce the precipitation response to the IPO in both the Amazonia and the Northeast regions can be partly related to the magnitude of the SSTA pattern, in particular to its tropical Pacific component. So, the higher the temperature in the tropical Pacific, the lower the precipitation anomalies in both regions and vice versa. In addition, no remarkable discrepancies between the forced and unforced simulations are found.

\subsubsection{Atmospheric teleconnection between IPO and rainfall}

The patterns of surface pressure during DJFMAM associated with the IPO in Figure 8 suggests a zonal and tropical atmospheric mechanism connecting the IPO to rainfall anomalies. It shows a weakening of pressure and convergent winds at 850 $\mathrm{hPa}$ over the Pacific and increased surface pressure across the rest of the tropical regions, spanning the Atlantic sector and eastern South America, similarly in observations and in both experiments. This is consistent with an anomalous Walker circulation, with associated increased ascending motion over the warm tropical Pacific and subsidence over the tropical Atlantic and northern South America (not shown). Such mechanism is similar to the teleconnection between the ENSO and the Amazonia and Northeast, which features subsidence over South America and induces rainfall decrease in both the Amazonia and Northeast regions (Ambrizzi et al 2004). Therefore, the large-scale observed atmospheric mechanism triggered by the IPO pattern is consistently reproduced by the models.

However, the moisture flux anomaly associated with the IPO pattern reveals certain differences between observed and the model-mean response over northern South America (Figures 8b, 8d and 8f, respectively). Observations show uncertain moisture flux anomalies over the Amazonia. However, there is anomalous moisture transport out of the Amazon river basin, over the tropical Atlantic, and south of the Amazonia, toward central Brazil and further south, that is consistent in both 
reanalysis (Figure 8b and supplementary Figure S1h). On the other hand, the model-mean anomalous moisture flux patterns show significant humidity transport from the tropical Atlantic toward the Northeast region. This is highly consistent between both historical and piControl experiments, slightly more intense in the latter. In contrast to the observations, the simulated moisture supply passes by the Northeast and the Amazonia regions all the way to the Pacific coast. As it passes over land the humidity supply increases, suggesting anomalous surface drying by means of more evaporation and less precipitation. To a lesser extent, there is also a southward moisture transport toward extratropical regions in agreement with the observations.

Regarding the surface pressure patterns in response to the IPO in detail, there are also local discrepancies between observations and simulations in the northernmost part of South America that could be related to the previously mentioned different behavior of the observed and simulated moisture flux. The models reproduce an anomalous low pressure center located in the northernmost part of South America, whilst in observations the surface pressure anomalies linked to the IPO are inconsistent between the different data used and, therefore, uncertain (Figure $8 \mathrm{a}$ and supplementary Figure S1f). This low surface pressure center simulated by the models might explain the unrealistic moisture intrusion from the tropical Atlantic. Nevertheless, the rainfall response to the IPO in observations and CMIP5 simulations is similar in both the Amazonia and Northeast regions. Such a scenario suggests that, even though there is humidity supplied by the Atlantic, the largescale induced subsidence inhibits convection in the models (e.g., Drumond et al 2010). In observations, the same mechanism of subsidence over the same regions is suggested to induce low-level divergence of moist air in the Northeast and further north affecting the Amazon region, producing further drought.

These discrepancies between observed and simulated regional mechanisms related with the IPO in the north of South America could be a consequence of insufficient resolution in areas of strong topographic change, or unresolved landatmosphere interactions in the models, which are highly relevant features in determining the South American climate (Labraga et al 2000; Grimm and Zilli 2009; Marengo et al 2012). They might be also related to the inherent noisy signal of the observational data. However, these discrepancies do not seem to influence the sign of the simulated rainfall response with respect to that observed in the Northeast and in most of the Amazonia region. But they are likely associated with the lack of precipitation anomalies in southwestern Amazon, with respect to observations, and could be highly relevant to resolve the climate variability of other extratropical regions that are also determined by the South American Monsoon System (Marengo et al 2012).

\subsection{Future scenario}

Despite the differences found among some models, the model-mean AMV and IPO patterns and their impacts on precipitation over Amazonia and Northeast regions show similar features as in observations in both forced and unforced simulations. On this basis, we can wonder whether the relationship between rainfall and the decadal-to-multidecadal patterns will change or not in a hypothetical future sce- 
nario analyzing the model-mean patters of CMIP5 future projections. To this aim, future projections of the RCP8.5 scenario are used.

Regarding the model-mean AMV pattern calculated with the RCP8.5 projection (Figure 9a), in the North Atlantic it depicts a coma-shape SSTA heating similar to the historical and piControl experiments, although slightly less consistent among the models and with lower statistical significance. The global pattern, however, presents colder anomalies than the one given by the historical experiment in the tropical Pacific, the Indian Ocean and the South Atlantic basin. It shows an interhemispheric thermal gradient in the Tropical Atlantic that resembles more to the AMV reproduced by the piControl simulation. Consistently, as in piControl, the response of precipitation anomalies to the AMV averaged across all models shows more agreement among them and more amplitude than in historical experiments, with positive anomalies over the Amazonia and negative ones in the Northeast region (Figure 9b). However, the statistical significance is notably low. Despite this, such distribution of rainfall anomalies suggests an anomalous northward shift of the rain-belt associated with the ITCZ during DJFMAM, which is also consistent with the associated atmospheric dynamic given by RCP8.5 projections: anomalous low pressure at the surface and low-level cyclonic circulation over the north Atlantic basin and northward strengthening of the cross-equatorial winds and of the moisture supply (supplementary Figure S8), consistently with the other two experiments.

The averaged IPO pattern of SSTA in the RCP8.5 projection is consistent with the ones in the historical and piControl experiments (Figures 9c, 6a and 6c). However there are more discrepancies among the models (Villamayor and Mohino 2015). Consistently, the rainfall response reproduced by the RCP8.5 simulation is noisier than the historical one (Figure 9d). The negative anomalies over the Amazonia region show very low statistical significance. In the Northeast the rainfall anomalies are uncertain, mostly negative in the interior but not significant. The associated atmospheric dynamics (supplementary Figure S9) coincides with the historical and piControl simulations but it is also less consistent among the models.

\section{Conclusions}

Our results suggest that both the AMV and the IPO long-term modes of SST variability are related to northern Brazilian rainfall during DJFMAM. In its positive phases, the AMV mode induces intensified rainfall in the Amazonia region and less precipitation in the Northeast, while the IPO hinders rainfall in both areas. Despite the shortcoming of observed precipitation data in these regions, especially in the Amazon basin and during the earliest period of the records (Marengo 2004), such a relationship is equally suggested by the three different databases analyzed (CRU TS3.24.01, GPCC v7 and UDEL v4.01), although low statistical significance is obtained in some cases. Hence, it is difficult to robustly determine the relationship between the decadal modes of SST variability and precipitation in observations. However, the analysis of 17 different CMIP5 models reveals that, on average, they reproduce the same basic features of the observed relationship between the lowfrequency SST modes of variability and rainfall in the northern Brazilian regions during DJFMAM, which reinforces the confidence in the observational results. Though the intensity of rainfall anomalies is notably underestimated. 
With regard to the AMV, its SSTA pattern depicts an interhemispheric thermal gradient in the Atlantic basin which induces opposite surface pressure anomalies at each hemisphere and anomalous latitudinal displacement of the ITCZ over the tropical Atlantic sector. In case of the positive AMV phase, during DJFMAM the ITCZ experiences a weaker intrusion toward the Northeast of Brazil remaining in latitudes close to the mouth of the Amazon, favoring moisture transport into the Amazonia. This mechanism produces anomalous drying in the Northeast region and wetter conditions in the Amazonia. The opposite occurs during the cold AMV phases.

There are some inconsistencies among the models with respect to the rainfall response to the AMV in the Amazonia and Northeast regions. This is related to the ability of the models to accurately reproduce the AMV pattern, particularly the characteristic interhemispheric thermal gradient in the Atlantic. In addition, there is also some discrepancy between the AMV impacts reproduced by the historical and the piControl experiments that is model-dependent. This may be related to the different ways in which the models resolve the aerosol effects in the historical experiment that can influence the AMV in some models and hence modify its pattern and impacts with respect to the one of piControl.

Regarding the IPO, the model-mean precipitation response during DJFMAM in the Amazonia and the Northeast regions is also similar to the observed one. During the positive phase of the IPO, the large-scale atmospheric mechanism observed as well as reproduced by the models is an anomalous Walker circulation, with increased convection over the warm tropical Pacific and subsidence over the Atlantic sector. This atmospheric connection hinders precipitation throughout the north of South America, in both observations and CMIP5 simulations. However, in observations the subsidence effect seems to block moist air intrusion from the tropical Atlantic, whilst in simulations the humidity flows zonally through the Northeast and the Amazonia regions, suggesting that in this case the subsidence hinders convection instead of blocking the moisture flux.

Despite the robustness of the IPO pattern of SSTA reproduced across the models (Villamayor and Mohino 2015), there are some discrepancies among the models in terms of the rainfall response. These are related to the way in which the models reproduce the more characteristic features of the IPO pattern, particularly the intensity of the tropical Pacific SSTA. However, in contrast to the AMV, there are not remarkable differences between the historical and piControl experiments related to the precipitation response to the IPO in the Amazonia and Northeast regions.

The analysis of the RCP8.5 experiment suggests that both the AMV and IPO patterns of SSTA reproduced by the models present the same characteristic features as in other experiments and in observations. Consistently, the RCP8.5 future projection broadly reproduces a rainfall response and an atmospheric mechanism similar to the one obtained in the other experiments for both SST modes. Such a result suggests that the AMV and IPO modes of SST variability and their impacts are not expected to change in the future, regardless of the concentration of greenhouse gases emitted. On the other hand, it should be pointed out that the low frequency variability of AMV and IPO may generate a weak signal in the 95 year period of the RCP8.5 projections. Thus their effect are less robustly captured across the models than in the other experiments (Villamayor and Mohino 2015). 
Further long period numerical experiments are still necessary to better understand such variability in the future.

The results show that the CMIP5 models on average can reproduce the main observed features, except for the strength, of the AMV and IPO patterns of SST and, consequently, their influence on precipitation in the Amazon and Northeast regions. It can thereby be suggested that an improvement of the ability of the global coupled models to reproduce the SST spatial pattern, the time evolution of the AMV and the IPO and their teleconnection with the atmosphere, will directly convert into a better simulation of the low-frequency variability of rainfall and an improved skill of the long-term forecasting in both the Amazonia and Northeast regions during the rainy season.

Acknowledgements The authors thank the editor Dr. Corti and the helpful comments of the two anonymous reviewers. This work is the result of a 3-month stay of J.V. in the University of São Paulo funded by the Spanish Ministry of Economy and Competitiveness (MINECO) with support for short stays (EEBB-I-15-09241-MINECO) within the scholarship he has been granted (BES-2013-063821-MINECO). Special thanks to Iracema F. A. Cavalcanti for making the stay possible and her helpful comments on the results. The research leading to these results has received funding from the projects PREFACE (EUFP7/2007-2013 Grant Agreement 603521) and MULCLIVAR (CGL2012-38923-C02-01-MINECO). T.A. had the financial support from FAPESP (Procs. Ns. 13/50521-7 and 08/58101-9) and CNPq. We acknowledge the World Climate Research Programme's Working Group on Coupled Modelling, which is responsible for CMIP, and the climate modeling groups (listed in the supplementary Table S1) for producing and making available their model output. For CMIP the U.S. Department of Energy's Program for Climate Model Diagnosis and Intercomparison provides coordinating support and led development of software infrastructure in partnership with the Global Organization for Earth System Science Portals.

\section{References}

Ambrizzi T, Souza EB, Pulwarty RS (2004) The Hadley and Walker regional circulations and associated ENSO impacts on South American seasonal rainfall. In: The Hadley circulation: Present, past and future, Springer, pp 203-235

Andreoli RV, Kayano MT (2005) ENSO-related rainfall anomalies in South America and associated circulation features during warm and cold Pacific decadal oscillation regimes. International Journal of Climatology 25(15):2017-2030, DOI 10.1002/joc. 1222

Booth BBB, Dunstone NJ, Halloran PR, Andrews T, Bellouin N (2012) Aerosols implicated as a prime driver of twentieth-century North Atlantic climate variability. Nature 484(7393):228-232, DOI 10.1038/nature10946, URL http://dx.doi.org/10.1038/nature10946

Chao Y, Ghil M, McWilliams JC (2000) Pacific interdecadal variability in this century's sea surface temperatures. Geophysical Research Letters 27(15):2261-2264, DOI 10.1029/1999GL011324, URL http://doi.wiley.com/10.1029/1999GL011324

Compo GP, Whitaker JS, Sardeshmukh PD, Matsui N, Allan RJ, Yin X, Gleason BE, Vose RS, Rutledge G, Bessemoulin P, et al (2011) The twentieth century reanalysis project. Quarterly Journal of the Royal Meteorological Society 137(654):1-28 
de Albuquerque Cavalcanti IF (2015) The influence of extratropical Atlantic Ocean region on wet and dry years in North-Northeastern Brazil. Frontiers in Environmental Science 3(April):1-10, DOI 10.3389/fenvs.2015.00034, URL http://journal.frontiersin.org/article/10.3389/fenvs.2015.00034/abstract

Deser C, Phillips AS, Hurrell JW (2004) Pacific interdecadal climate variability: Linkages between the tropics and the North Pacific during boreal winter since 1900. Journal of Climate 17(16):3109-3124, DOI 10.1175/15200442(2004)017;3109:PICVLB ¿2.0.CO;2

Dettinger M, Battisti D, McCabe G, Bitz C, Garreaud R (2001) Interhemispheric effects of interannual and decadal ENSO-like climate variations on the Americas. Interhemispheric climate linkages: Present and Past Climates in the Americas and their Societal Effects pp 1-16, URL http://www.atmos.washington.edu/\%7B \%7Ddavid/pep1.pdf

Doblas-Reyes F, Andreu-Burillo I, Chikamoto Y, Garc\{\’’i\}a-Serrano J, Guemas V, Kimoto M, Mochizuki T, Rodrigues L, Oldenborgh GJV (2013) Initialized near-term regional climate change prediction. Nature communications 4:1715, DOI $10.1038 /$ ncomms2704

Drumond A, Nieto R, Trigo R, Ambrizzi T, Souza E, Gimeno L (2010) A lagrangian identification of the main sources of moisture affecting northeastern brazil during its pre-rainy and rainy seasons. PloS one 5(6):e11,205

Ebisuzaki W (1997) A method to estimate the statistical significance of a correlation when the data are serially correlated. Journal of Climate 10(9):2147-2153

Farneti R (2017) Modelling interdecadal climate variability and the role of the ocean. Wiley Interdisciplinary Reviews: Climate Change 8(1)

Farneti R, Molteni F, Kucharski F (2014) Pacific interdecadal variability driven by tropicalextratropical interactions. Climate Dynamics 42(11-12):3337-3355, DOI 10.1007/s00382-013-1906-6, URL http://link.springer.com/10.1007/s00382-0131906-6

Folland CK, Colman aW, Rowell DP, Davey MK (2001) Predictability of northeast Brazil rainfall and real-time forecast skill, 1987-98. Journal of Climate 14(9):1937-1958, DOI 10.1175/1520-0442(2002)015¡1993:NOPONB ¿2.0.CO;2

Fuentes-Franco R, Giorgi F, Coppola E, Fred K (2015) The role of ENSO and PDO in variability of winter precipitation over North America from twenty first century CMIP5 projections. Climate Dynamics 17:1-19, DOI 10.1007/s00382015-2767-y

Gaetani M, Mohino E (2013) Decadal Prediction of the Sahelian Precipitation in CMIP5 Simulations. Journal of Climate 26(19):7708-7719, DOI 10.1175/JCLID-12-00635.1

Good P, Lowe Ja, Collins M, Moufouma-Okia W (2008) An objective tropical Atlantic sea surface temperature gradient index for studies of south Amazon dry-season climate variability and change. Philosophical transactions of the Royal Society of London Series B, Biological sciences 363(1498):1761-1766, DOI 10.1098/rstb.2007.0024

Grimm AM, Zilli MT (2009) Interannual variability and seasonal evolution of summer monsoon rainfall in South America. Journal of Climate 22(9):22572275, DOI 10.1175/2008JCLI2345.1

Harris I, Jones P, Osborn T, Lister D (2014) Updated high-resolution grids of monthly climatic observations-the cru ts3. 10 dataset. International Journal of Climatology 34(3):623-642 
Hastenrath S (2012) Exploring the climate problems of Brazil's Nordeste: A review. Climatic Change 112(2):243-251, DOI 10.1007/s10584-011-0227-1

Hastenrath S, Greischar L (1993) Circulation mechanisms related to northeast Brazil rainfall anomalies. Journal of Geophysical Research: Atmospheres 98:5093-5102

Hastenrath S, Heller L (1977) Dynamics of climatic hazards in northeast Brazil. DOI 10.1002/qj.49710343505

Hawkins E, Robson J, Sutton R, Smith D, Keenlyside N (2011) Evaluating the potential for statistical decadal predictions of sea surface temperatures with a perfect model approach. Climate dynamics 37(11-12):2495-2509

Haywood JM, Jones A, Bellouin N, Stephenson D (2013) Asymmetric forcing from stratospheric aerosols impacts Sahelian rainfall. Nature Climate Change 3(7):660-665, DOI 10.1038/nclimate1857, URL http://www.nature.com/doifinder/10.1038/nclimate1857

Joshi MK, Kucharski F (2017) Impact of interdecadal pacific oscillation on indian summer monsoon rainfall: an assessment from cmip5 climate models. Climate Dynamics 48(7-8):2375-2391

Kayano MT, Andreoli RV (2006) Relationships between rainfall anomalies over northeastern Brazil and the El Niño-Southern Oscillation. Journal of Geophysical Research Atmospheres 111(13):1-11, DOI 10.1029/2005JD006142

Kerr RA (2000) A north atlantic climate pacemaker for the centuries. Science (New York, NY) 288(5473):1984-1985, DOI 10.1126/science.288.5473.1984

Knight JR (2005) A signature of persistent natural thermohaline circulation cycles in observed climate. Geophysical Research Letters 32(20):L20,708, DOI 10.1029/2005GL024233, URL http://doi.wiley.com/10.1029/2005GL024233

Knight JR, Folland CK, Scaife AA (2006) Climate impacts of the Atlantic Multidecadal Oscillation. Geophysical Research Letters 33(17):L17,706, DOI 10.1029/2006GL026242, URL http://doi.wiley.com/10.1029/2006GL026242

Kousky VE (1979) Frontal Influences on Northeast Brazil. DOI 10.1175/15200493(1979)107;1140:FIONB $\underset{i}{2} .0 . C O ; 2$

Labraga JC, Frumento O, López M (2000) The Atmospheric Water Vapor Cycle in South America and the Tropospheric Circulation. American Meteorological Society 13(11):1899-1915

Latif M, Keenlyside NS (2011) A perspective on decadal climate variability and predictability. Deep Sea Research Part II: Topical Studies in Oceanography 58(17):1880-1894

Levine AF, McPhaden MJ, Frierson DM (2017) The impact of the amo on multidecadal enso variability. Geophysical Research Letters 44(8):3877-3886

MacDonald GM, Case RA (2005) Variations in the Pacific Decadal Oscillation over the past millennium. Geophysical Research Letters 32(8):L08,703, DOI 10.1029/2005GL022478, URL http://doi.wiley.com/10.1029/2005GL022478

Mantua NJ, Hare SR (2002) The Pacific decadal oscillation. Journal of Oceanography 58(1):35-44, DOI 10.1023/a:1015820616384

Mantua NJ, Hare SR, Zhang Y, Wallace JM, Francis RC (1997) A Pacific Interdecadal Climate Oscillation with Impacts on Salmon Production. Bulletin of the American Meteorological Society 78(6):1069-1079, DOI 10.1175/15200477(1997)078;1069:APICOW ¿2.0.CO;2

Marengo JA (2004) Interdecadal variability and trends of rainfall across the Amazon basin. Theoretical and Applied Climatology 78(1-3):79-96, DOI 
10.1007/s00704-004-0045-8, URL http://link.springer.com/10.1007/s00704-0040045-8

Marengo JA (2009) Long-term trends and cycles in the hydrometeorology of the amazon basin since the late 1920s. Hydrological Processes 23(22):3236-3244

Marengo Ja, Tomasella J, Uvo CR (1998) Trends in streamflow and rainfall in tropical South America: Amazonia, eastern Brazil, and northwestern Peru. Journal of Geophysical Research 103(D2):1775, DOI 10.1029/97JD02551

Marengo JA, Liebmann B, Grimm AM, Misra V, Dias PLS, Cavalcanti IFA, Carvalho LMV, Berbery EH, Ambrizzi T, Vera CS, Saulo AC, Nogues-paegle J, Zipser E, Seth A, Alves LM (2012) Recent developments on the South American monsoon system. International Journal of Climatology 32(1):1-21, DOI $10.1002 /$ joc. 2254

Martin ER, Thorncroft C, Booth BBB (2014) The Multidecadal Atlantic SST-Sahel Rainfall Teleconnection in CMIP5 Simulations. Journal of Climate 27(2):784-806, DOI 10.1175/JCLI-D-13-00242.1, URL http://journals.ametsoc.org/doi/abs/10.1175/JCLI-D-13-00242.1

McCarthy GD, Haigh ID, Hirschi JJM, Grist JP, Smeed Da (2015) Ocean impact on decadal Atlantic climate variability revealed by sealevel observations. Nature 521(7553):508-510, DOI 10.1038/nature14491, URL http://www.nature.com/doifinder/10.1038/nature14491

Meehl Ga, Hu A (2006) Megadroughts in the Indian monsoon region and southwest North America and a mechanism for associated multidecadal Pacific Sea surface temperature anomalies. Journal of Climate 19(9):1605-1623, DOI 10.1175/JCLI3675.1

Meehl GA, Goddard L, Murphy J, Stouffer RJ, Boer G, Danabasoglu G, Dixon K, Giorgetta MA, Greene AM, Hawkins E, et al (2009a) Decadal prediction: can it be skillful? Bulletin of the American Meteorological Society 90(10):1467-1485

Meehl GA, Hu A, Santer BD (2009b) The Mid-1970s Climate Shift in the Pacific and the Relative Roles of Forced versus Inherent Decadal Variability. Journal of Climate 22(3):780-792, DOI 10.1175/2008JCLI2552.1, URL http://journals.ametsoc.org/doi/abs/10.1175/2008JCLI2552.1

Minobe S (1999) Resonance in bidecadal and pentadecadal climate oscillations over the North Pacific: Role in climatic regime shifts. Geophysical Research Letters 26(7):855-858, DOI 10.1029/1999GL900119

Mohino E, Janicot S, Bader J (2011) Sahel rainfall and decadal to multi-decadal sea surface temperature variability. Climate Dynamics 37(3-4):419-440, DOI 10.1007/s00382-010-0867-2, URL http://link.springer.com/10.1007/s00382-0100867-2

Moura AD, Shukla J (1981) On the dynamics of droughts in Northeast Brazil: Observations, theory, and numerical experiments with a general circulation model. DOI http://dx.doi.org/10.1175/1520-0469(1981)038¡2653:OTDODI_.2.0.CO;2

Newman M (2013) An empirical benchmark for decadal forecasts of global surface temperature anomalies. Journal of Climate 26(14):5260-5269

Newman M, Compo GP, Alexander MA (2003) ENSO-forced variability of the Pacific decadal oscillation. Journal of Climate 16(23):3853-3857, DOI 10.1175/1520-0442(2003)016¡3853:EVOTPD ¿2.0.CO;2

Newman M, Alexander MA, Ault TR, Cobb KM, Deser C, Di Lorenzo E, Mantua NJ, Miller AJ, Minobe S, Nakamura H, et al (2016) The pacific decadal oscillation, revisited. Journal of Climate 29(12):4399-4427 
Nobre P, Shukla J (1996) Variations of Sea Surface Temperature, Wind Stress, and Rainfall over the Tropical Atlantic and South America. Journal of Climate 9(10):2464-2479, DOI 10.1175/1520-0442(1996)009;2464:VOSSTW ¿2.0.CO;2

van Oldenborgh GJ, Doblas-Reyes FJ, Wouters B, Hazeleger W (2012) Decadal prediction skill in a multi-model ensemble. Climate dynamics 38(7-8):1263-1280

Parker D, Folland C, Scaife A, Knight J, Colman A, Baines P, Dong B (2007) Decadal to multidecadal variability and the climate change background. Journal of Geophysical Research: Atmospheres 112(18):1-18, DOI 10.1029/2007JD008411

Philander SG (1990) El niño, la niña, and the southern oscillation

Poli P, Hersbach H, Tan D, Dee D, Thépaut Jn, Simmons A, Peubey C, Laloyaux P, Komori T, Berrisford P, Dragani R (2013) ERA report series p 59, URL http://rda.ucar.edu/datasets/ds626.0/docs/ERA-20C.era_report_series_14.pdf

Power S, Casey T, Folland C, Colman a, Mehta V (1999) Inter-decadal modulation of the impact of ENSO on Australia. Climate Dynamics 15(5):319-324, DOI $10.1007 / \mathrm{s} 003820050284$

Rao VB, Hada K (1990) Characteristics of rainfall over Brazil: Annual variations and connections with the Southern Oscillation. Theoretical and Applied Climatology 42:81-91, DOI 10.1007/BF00868215

Rayner NA, Parker DE, Horton EB, Folland CK, Alexander LV, Rowell DP (2003) Global analyses of sea surface temperature, sea ice, and night marine air temperature since the late nineteenth century. Journal of Geophysical Research 108(D14):4407, DOI 10.1029/2002JD002670, URL http://doi.wiley.com/10.1029/2002JD002670

Riahi K, Grübler A, Nakicenovic N (2007) Scenarios of long-term socio-economic and environmental development under climate stabilization. Technological Forecasting and Social Change 74:887-935, DOI 10.1016/j.techfore.2006.05.026

Robertson AW, Mechoso CR (1998) Interannual and Decadal Cycles in River Flows of Southeastern South America. Journal of Climate 11:2570-2581

Rodrigues RR, Haarsma RJ, Campos EJD, Ambrizzi T (2011) The impacts of inter-El Niño variability on the tropical Atlantic and northeast Brazil climate. Journal of Climate 24(13):3402-3422, DOI 10.1175/2011JCLI3983.1

Ronchail J, Cochonneau G, Molinier M, Guyot JL, De Miranda Chaves AG, Guimarães V, De Oliveira E (2002) Interannual rainfall variability in the Amazon basin and sea-surface temperatures in the equatorial Pacific and the tropical Atlantic Oceans. International Journal of Climatology 22(13):1663-1686, DOI $10.1002 /$ joc. 815

Rotstayn LD, Lohmann U (2002) Tropical rainfall trends and the indirect aerosol effect. Journal of Climate 15(15):2103-2116, DOI 10.1175/15200442(2002)015;2103:TRTATi ¿2.0.CO;2

Schneider N, Cornuelle BD (2005) The forcing of the Pacific Decadal Oscillation. Journal of Climate 18(21):4355-4373, DOI 10.1175/JCLI3527.1, URL http://journals.ametsoc.org/doi/abs/10.1175/JCLI3527.1

Schneider U, Becker A, Finger P, Meyer-Christoffer A, Rudolf B, Ziese M (2016) Gpcc full data reanalysis version 7.0: Monthly land-surface precipitation from rain gauges built on gts based and historic data. URL https://doi.org/10.5065/D6000072

Shakun JD, Shaman J (2009) Tropical origins of North and South Pacific decadal variability. Geophysical Research Letters 36(19):L19,711, DOI 
10.1029/2009GL040313, URL http://doi.wiley.com/10.1029/2009GL040313

da Silva VdPR (2004) On climate variability in Northeast of Brazil. Journal of Arid Environments 58(4):575-596, DOI 10.1016/j.jaridenv.2003.12.002, URL http://linkinghub.elsevier.com/retrieve/pii/S0140196303001794

Souza EB, Ambrizzi T (2002) ENSO impacts on the South American rainfall during 1980s: Hadley and Walker circulation. Atmósfera 15(2):105-120

Taylor KE, Stouffer RJ, Meehl Ga (2012) An overview of CMIP5 and the experiment design. Bulletin of the American Meteorological Society 93(4):485-498, DOI 10.1175/BAMS-D-11-00094.1

Terray L (2012) Evidence for multiple drivers of North Atlantic multi-decadal climate variability. Geophysical Research Letters 39(October):6-11, DOI 10.1029/2012GL053046

Tourre YM, Rajagopalan B, Kushnir Y, Barlow M, White WB (2001) Patterns of coherent decadal and interdecadal climate signals in the Pacific Basin during the 20 th century. DOI 10.1029/2000GL012780

Trenberth KE, Hurrell JW (1994) Decadal atmosphere-ocean variations in the Pacific. Climate Dynamics 9:303-319, DOI 10.1007/BF00204745, 0601117

Villamayor J, Mohino E (2015) Robust Sahel drought due to the Interdecadal Pacific Oscillation in CMIP5 simulations. Geophysical Research Letters 42(4):1214-1222, DOI 10.1002/2014GL062473, URL http://doi.wiley.com/10.1002/2014GL062473

Wainer I, Soares J (1997) North northeast Brazil rainfall and its decadal\&\#8208;scale relationship to wind stress and sea surface temperature 24(3):277-280

Willmott CJ, Matsuura K, Legates D (2001) Terrestrial air temperature and precipitation: monthly and annual time series (1950-1999). Center for climate research version 1

Wu S, Liu Z, Zhang R, Delworth TL (2011) On the observed relationship between the pacific decadal oscillation and the atlantic multi-decadal oscillation. Journal of oceanography $67(1): 27-35$

Yim BY, Kwon M, Min HS, Kug JS (2015) Pacific Decadal Oscillation and its relation to the extratropical atmospheric variation in CMIP5. Climate Dynamics 44(5-6):1521-1540, DOI 10.1007/s00382014-2349-4, URL http://link.springer.com/10.1007/s00382-014-23494\%5Cnpapers3://publication/doi/10.1007/s00382-014-2349-4

Yin L, Fu R, Shevliakova E, Dickinson RE (2013) How well can cmip5 simulate precipitation and its controlling processes over tropical south america? Climate Dynamics 41(11-12):3127-3143

Yoon JH, Zeng N (2010) An Atlantic influence on Amazon rainfall. Climate Dynamics 34(2):249-264, DOI 10.1007/s00382-009-0551-6

Zhang L, Delworth TL (2015) Analysis of the characteristics and mechanisms of the pacific decadal oscillation in a suite of coupled models from the geophysical fluid dynamics laboratory. Journal of climate 28(19):7678-7701

Zhang L, Wang C (2013) Multidecadal North Atlantic sea surface temperature and Atlantic meridional overturning circulation variability in CMIP5 historical simulations. Journal of Geophysical Research: Oceans 118(10):5772-5791, DOI 10.1002/jgrc.20390

Zhang R, Delworth TL (2007) Impact of the atlantic multidecadal oscillation on north pacific climate variability. Geophysical Research Letters 34(23) 
Zhang R, Delworth TL, Sutton R, Hodson DLR, Dixon KW, Held IM, Kushnir Y, Marshall J, Ming Y, Msadek R, Robson J, Rosati AJ, Ting M, Vecchi GA (2013) Have Aerosols Caused the Observed Atlantic Multidecadal Variability? Journal of the Atmospheric Sciences 70(4):1135-1144, DOI 10.1175/JAS-D-12-0331.1, URL http://journals.ametsoc.org/doi/abs/10.1175/JAS-D-12-0331.1

Zhang Y, Wallace JM, Battisti DS (1997) ENSO-like interdecadal variability: 1900-93. Journal of Climate 10(5):1004-1020, DOI 10.1175/15200442(1997)010¡1004:ELIV ¿2.0.CO;2

Zhou J, Lau KM (2001) Principal modes of interannual and decadal variability of summer rainfall over South America. International Journal of Climatology 21(13):1623-1644, DOI 10.1002/joc.700 
Table 1 List of CMIP5 models used, number of years (\#years) or period analyzed and number of realizations (\#rea) of each simulation. *More details about modeling groups in supplementary Table S1. All data available at http://pcmdi9.llnl.gov.

\begin{tabular}{lcccccc}
\hline & piControl & \multicolumn{2}{c}{ historical } & \multicolumn{2}{c}{ RCP8.5 } \\
\cline { 2 - 5 } Model Name* & \#years & period & \#rea & period & \#rea \\
\hline 1. bcc-csm1-1 & 500 & $1850-2012$ & 3 & $2006-2100$ & 1 \\
2. CanESM2 & 996 & $1850-2005$ & 5 & $2006-2100$ & 5 \\
3. CCSM4 & 501 & $1850-2005$ & 6 & $2006-2100$ & 6 \\
4. CNRM-CM5 & 850 & $1850-2005$ & 10 & $2006-2100$ & 5 \\
5. CSIRO-Mk3-6-0 & 500 & $1850-2005$ & 10 & $2006-2100$ & 10 \\
6. FGOALS-g2 & 700 & $1850-2005$ & 4 & $2006-2100$ & 1 \\
7. GISS-E2-H & 540 & $1850-2005$ & 5 & $2006-2100$ & 5 \\
8. GISS-E2-R & 550 & $1850-2005$ & 6 & $2006-2100$ & 5 \\
9. HadGEM2-CC & 240 & $1860-2004$ & 1 & $2006-2099$ & 3 \\
10. HadGEM2-ES & 575 & $1860-2004$ & 5 & $2006-2100$ & 4 \\
11. inmcm4 & 500 & $1850-2005$ & 1 & $2006-2100$ & 1 \\
12. IPSL-CM5A-LR & 1000 & $1850-2005$ & 6 & $2006-2100$ & 4 \\
13. MIROC5 & 670 & $1850-2012$ & 5 & $2006-2100$ & 3 \\
14. MIROC-ESM-CHEM & 255 & $1850-2005$ & 1 & $2006-2100$ & 1 \\
15. MPI-ESM-LR & 1000 & $1850-2005$ & 3 & $2006-2100$ & 3 \\
16. MRI-CGCM3 & 500 & $1850-2005$ & 5 & $2006-2100$ & 1 \\
17. NorESM1-M & 501 & $1850-2005$ & 3 & $2006-2100$ & 1 \\
\hline
\end{tabular}
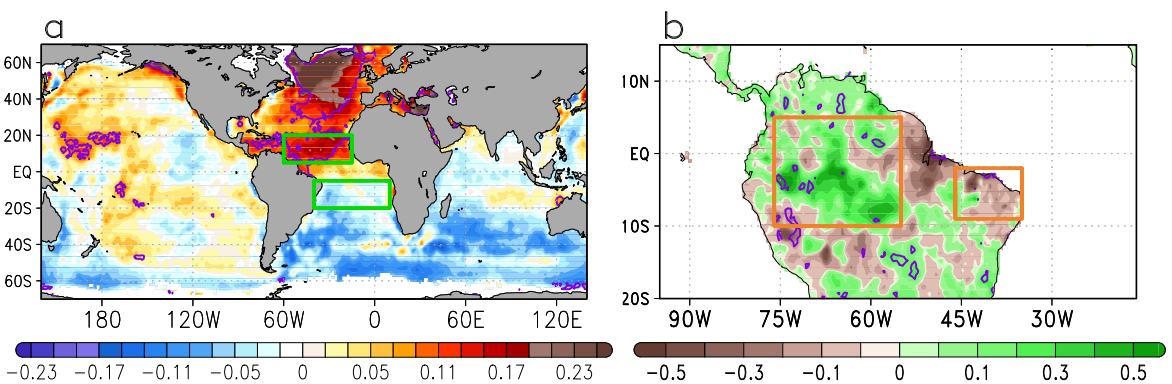

Fig. 1 (a) Regression pattern of the unfiltered SSTA from HadISST1 onto the standardized AMV index (units are K per standard deviation). (b) Regression map of the unfiltered DJFMAM precipitation anomaly from GPCC v7 onto the standardized AMV index (units are $\mathrm{mm}$ /day per standard deviation). Contours indicate the regions where the regression is significant at the $10 \%$ level. 

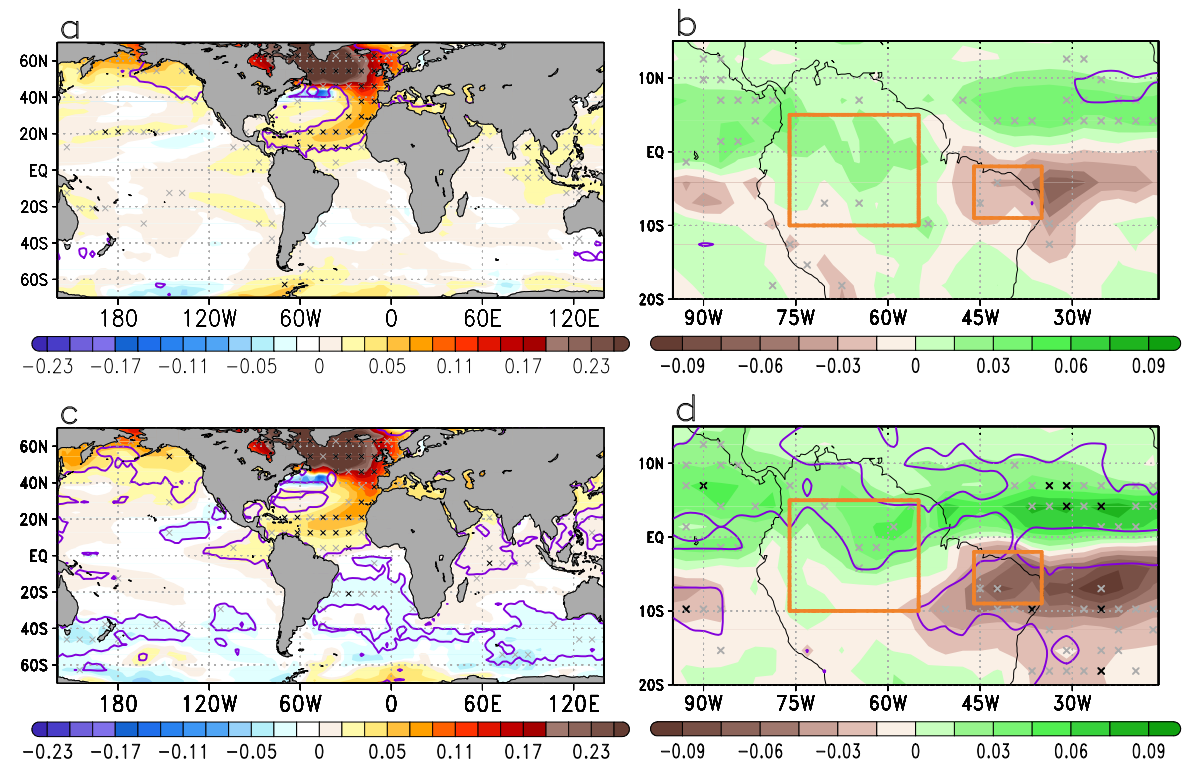

Fig. 2 Regression onto the AMV index of the unfiltered (a) SSTA (K per std. dev.) and (b) DJFMAM precipitation anomalies (mm/day per std. dev.) averaged among the 17 CMIP5 models in the historical run, typically from 1850-2005 (details in Table 1). (c) and (d) same as (a) and (b), respectively, but in the piControl run. Black and grey marks indicate points where the regression coefficient sign coincides in at least 15 and 13 out of the 17 models analyzed, respectively. Contours indicate the regions where the averaged regression is significant at the $5 \%$ level. 


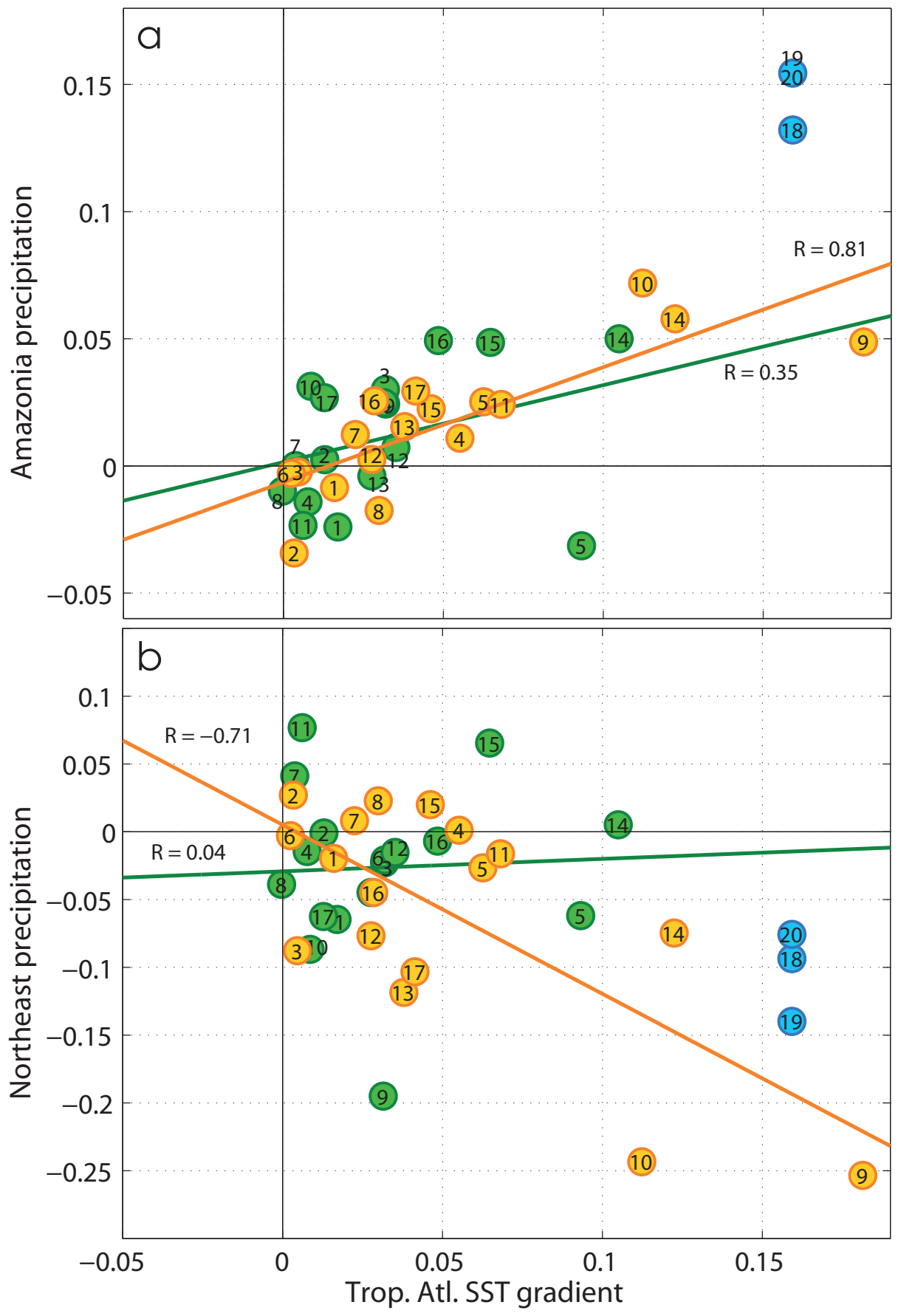

Fig. 3 (a) Scatterplot of the regression coefficient of precipitation anomaly over the Amazonia (between $10^{\circ} \mathrm{S}-5^{\circ} \mathrm{N}$ and $\left.76^{\circ}-55^{\circ} \mathrm{W}\right)$ and the SSTA tropical Atlantic gradient $\left(5^{\circ}-20^{\circ} \mathrm{N}\right.$ and $60^{\circ}-15^{\circ} \mathrm{W}$ minus $20^{\circ}-5^{\circ} \mathrm{S}$ and $40^{\circ} \mathrm{W}-10^{\circ} \mathrm{E}$ ) relative to the AMV of each model in the historical (green) and the piControl (orange) simulations (supplementary Figures S2, S3, S4 and S5). The lines indicate the linear regression fitting of the corresponding coloured points ( $\mathrm{R}$ is the correlation coefficient). The numbers from 1 to 17 identify each model individually with the given number in Table 1. (b) Same as (a) but using the Northeast region (between $46^{\circ}-35^{\circ} \mathrm{W}$ and $9^{\circ}-2^{\circ} \mathrm{S}$ ) instead of the Amazonia. Numbers 18,19 and 20 correspond to CRU TS3.24.01, GPCC v7 and UDEL v4.01 observed data, respectively. Units for the horizontal and vertical axes are $\mathrm{mm} /$ day per standard deviation and ${ }^{\circ} \mathrm{C}$ per standard deviation), respectively. 

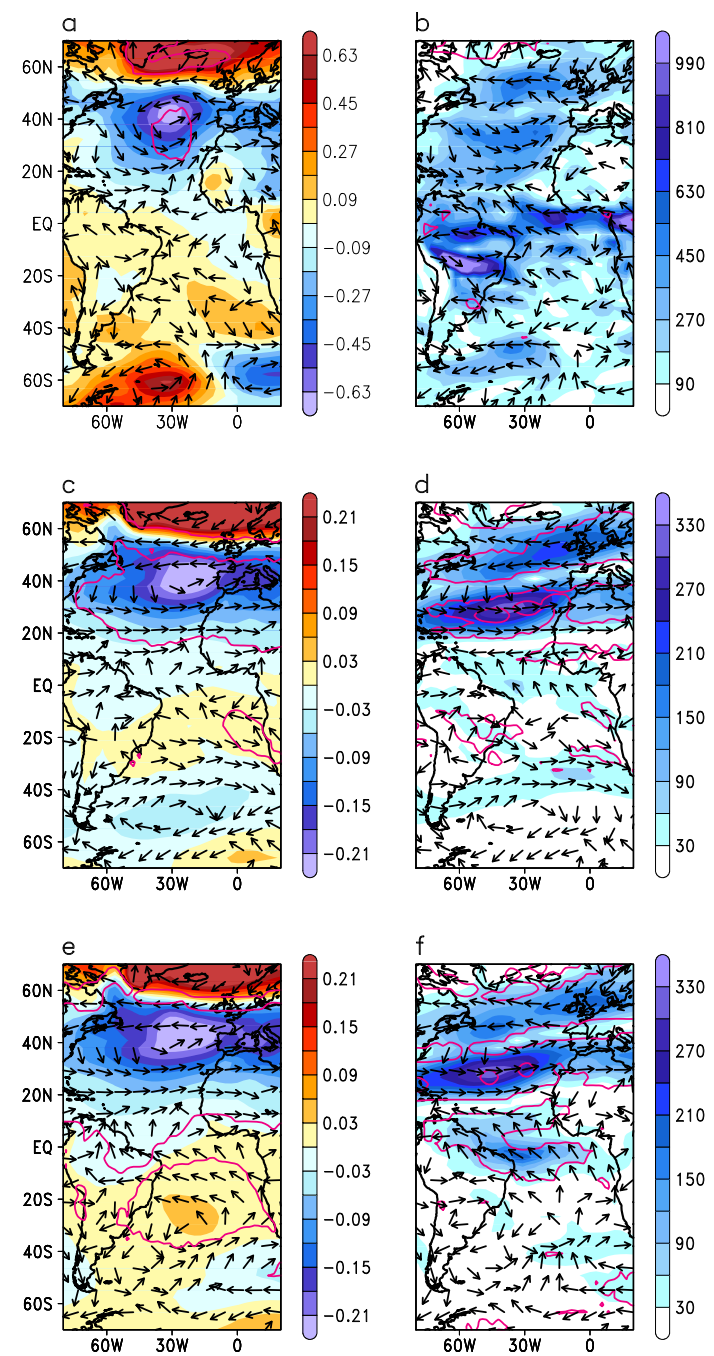

Fig. 4 Regression onto the observed AMV index of the unfiltered DJFMAM anomaly of the surface pressure (shaded) (hPa per std. dev.) and the wind direction at $850 \mathrm{hPa}$ (vectors) in (a); and the magnitude (shaded) and direction (vectors) of the moisture flux integrated from surface to $200 \mathrm{hPa}(\mathrm{kg} / \mathrm{m} /$ day per std. dev.) in (b) from the ERA-20C reanalysis. (c) and (d) same as (a) and (b), respectively, but using the historical simulations and averaged among the 17 CMIP5 models. (e) and (f) same as (c) and (d) but for piControl simulations. The color scale changes from observations $(a-b)$ to simulations $(c-f)$. Contours indicate the regions where the regression is significant at the $10 \%$ (a-b) and $5 \%$ (c-f) level. 

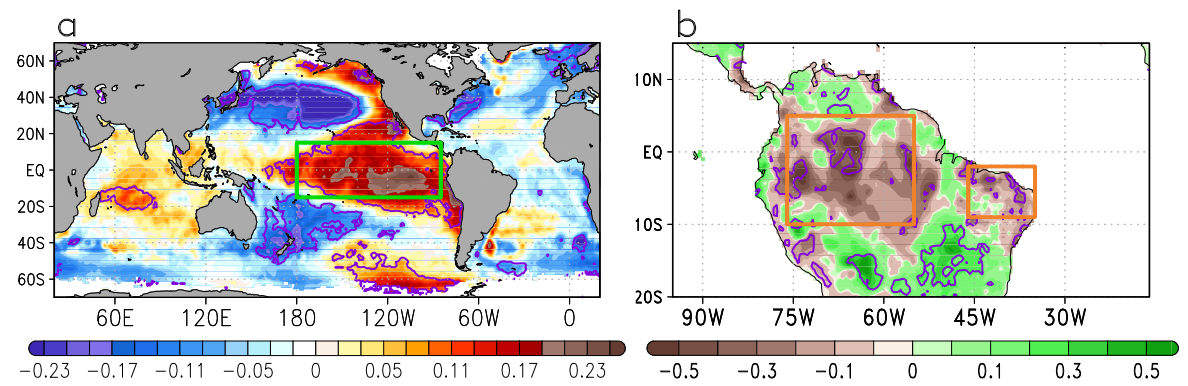

Fig. 5 (a) Regression pattern of the unfiltered SSTA from HadISST1 onto the standardized IPO index (units are K per standard deviation). (b) Regression map of the unfiltered DJFMAM precipitation anomaly from GPCC $\mathrm{v} 7$ onto the standardized IPO index (units are $\mathrm{mm} /$ day per standard deviation). Contours indicate the regions where the regression is significant at the $10 \%$ level.
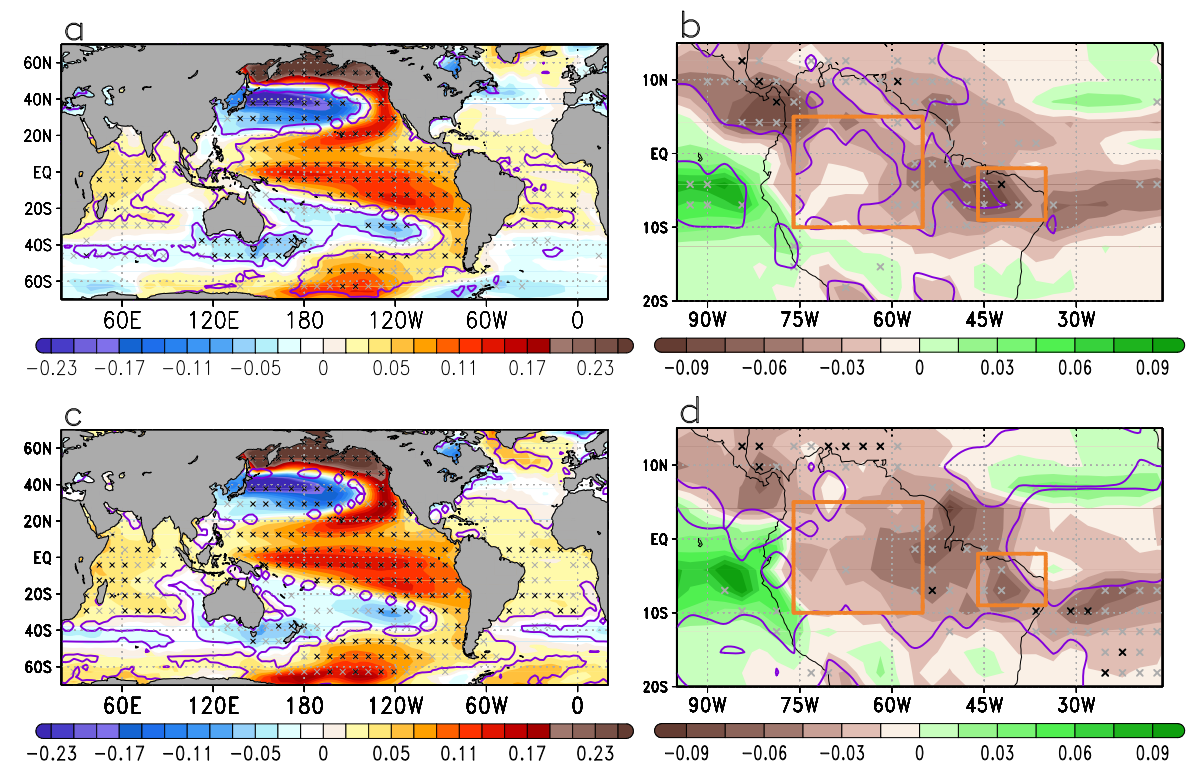

Fig. 6 Regression onto the IPO index of the unfiltered (a) SSTA (K per std. dev.) and (b) DJFMAM precipitation anomalies (mm/day per std. dev.) averaged among the 17 CMIP5 models in the historical run. (c) and (d) same as (a) and (b), respectively, but in the piControl run. Black and grey marks indicate points where the regression coefficient sign coincides in at least 15 and 13 out of the 17 models analyzed, respectively. Contours indicate the regions where the averaged regression is significant at the $5 \%$ level. 


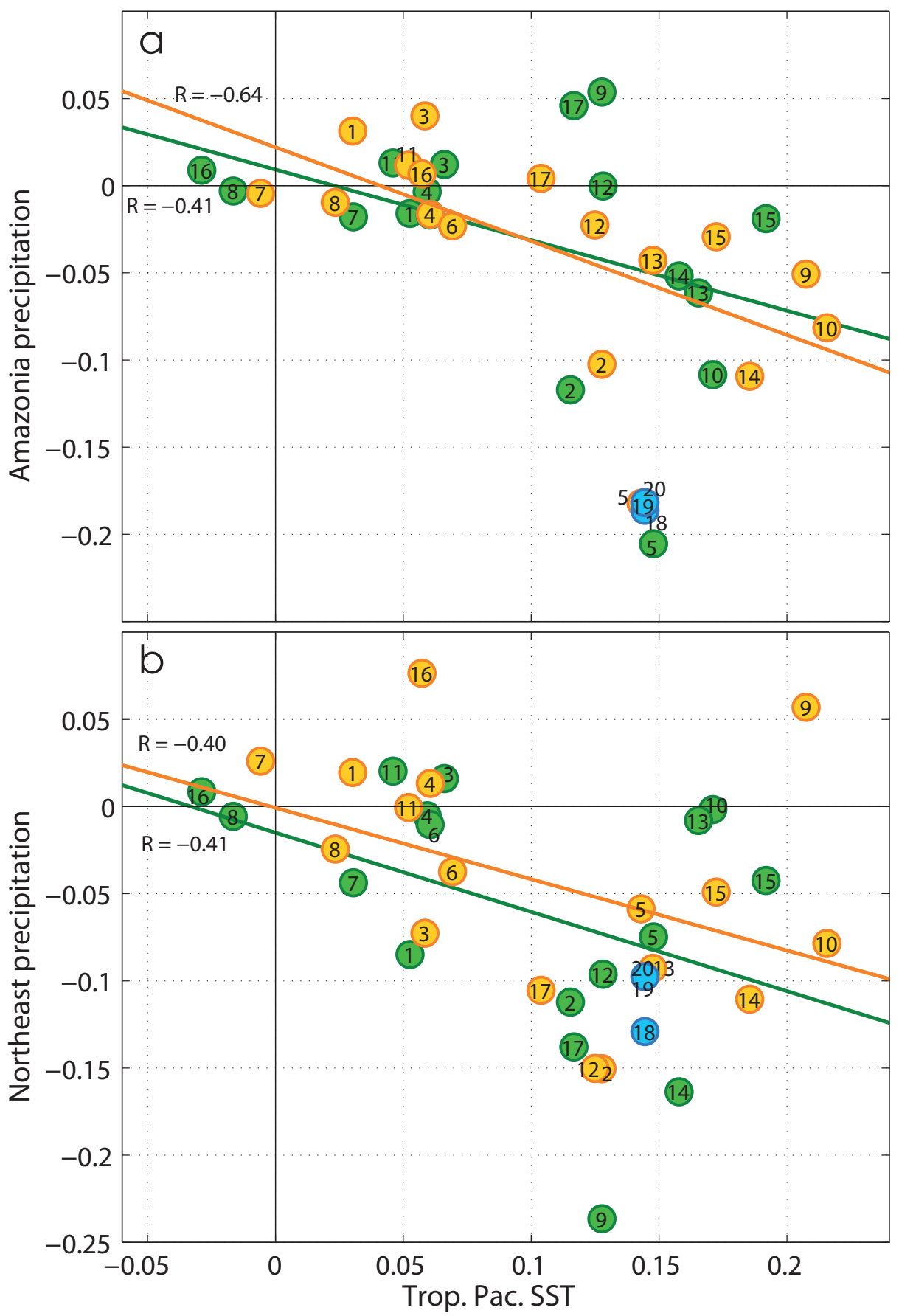

Fig. 7 Same as Figure 3 but plotting the regression coefficient from the individual-model IPO patterns of the precipitation anomaly in the Amazonia and Northeast (supplementary Figures S6 and S7) against the SSTA of the tropical Pacific (between $15^{\circ} \mathrm{S}-15^{\circ} \mathrm{N}$ and $180^{\circ}$ $\left.95^{\circ} \mathrm{W}\right)$, instead of the tropical Atlantic gradient. 

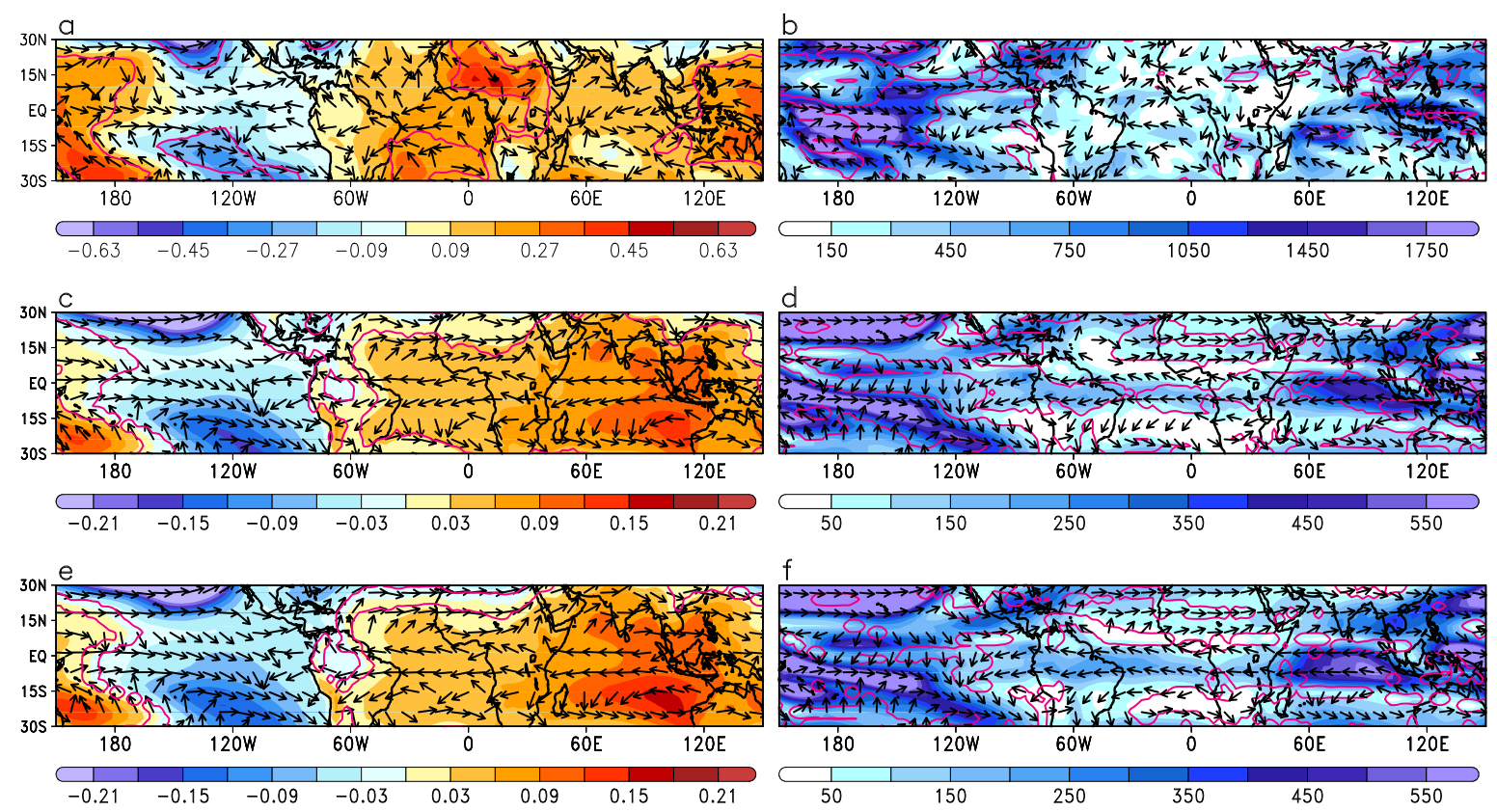

Fig. 8 Regression onto the observed IPO index of the unfiltered DJFMAM anomaly of the surface pressure (shaded)(hPa per std. dev.) and the wind direction at $850 \mathrm{hPa}$ (vectors) in (a); and the magnitude (shaded) and direction (vectors) of the moisture flux integrated from surface to $200 \mathrm{hPa}(\mathrm{kg} / \mathrm{m} /$ day per std. dev.) in (b) from the ERA-20C reanalysis. (c) and (d) same as (a) and (b), respectively, but using the historical simulations and averaged among the 17 CMIP5 models. (e) and (f) same as (c) and (d) but for piControl simulations. The color scale changes from observations (a-b) to simulations (c-f). Contours indicate the regions where the regression is significant at the $10 \%(\mathrm{a}-\mathrm{b})$ and $5 \%(\mathrm{c}-\mathrm{f})$ level. 

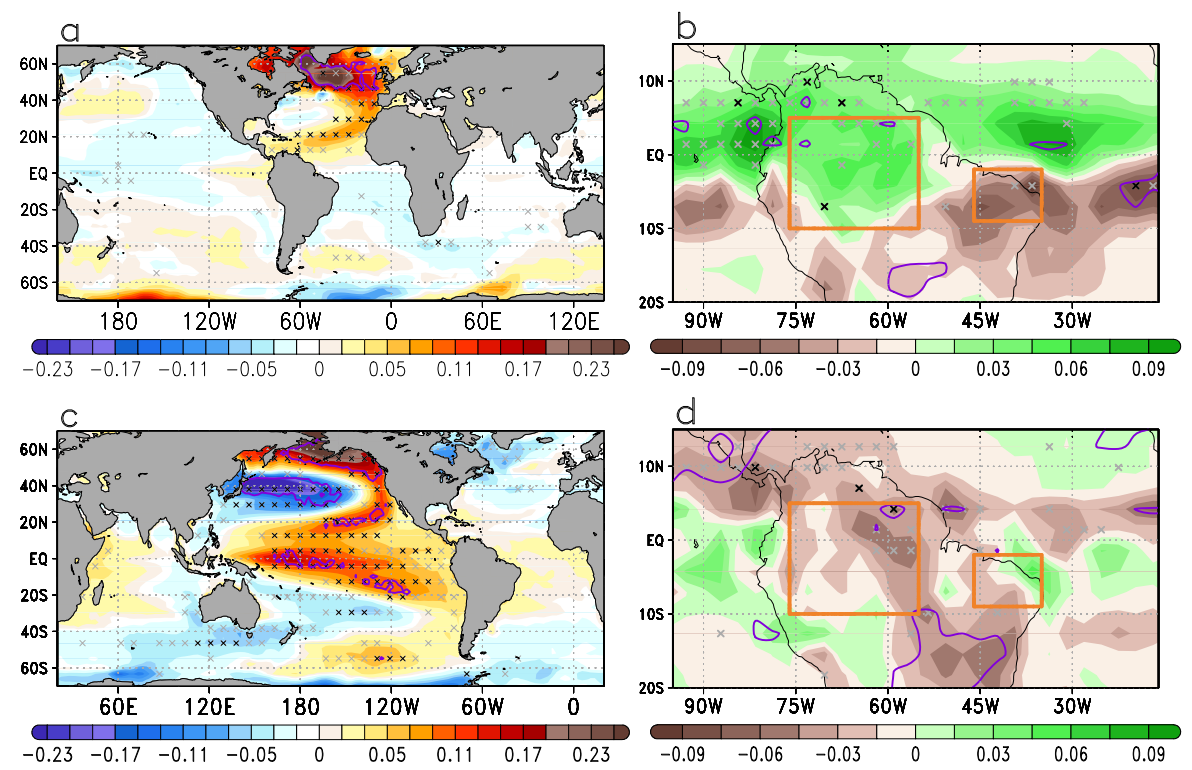

Fig. 9 Regression of the unfiltered (a) SSTA (K per std. dev.) and (b) DJFMAM precipitation anomalies (mm/day per std. dev.) averaged among the 17 CMIP5 models in the RCP8.5 future projection onto the AMV index. (c) and (d) same as (a) and (b), respectively, but regressing onto the IPO index. Black and grey marks indicate points where the regression coefficient sign coincides in at least 15 and 13 out of the 17 models analyzed, respectively. Contours indicate the regions where the regression is significant at the $5 \%$ level. 